\title{
Résumé du programme Surveillance de l'influenza : 8 au 14 février 2015 (semaine 6)
}

\author{
Lee $L^{1 *}$, Saboui $M^{1}$, Mersereau $T^{1}$ \\ ${ }^{1}$ Centre de l'immunisation et des maladies respiratoires infectieuses, Agence de la santé publique du Canada, Ottawa \\ (Ontario) \\ * Auteure-ressource : Liza.Lee@phac-aspc.gc.ca
}

\section{Résumé}

Objectif : fournir un résumé du rapport hebdomadaire Surveillance de l'influenza portant sur l'activité grippale au Canada, pour la semaine du 8 au 14 février 2015.

Méthodologie : Le programme Surveillance de l'influenza consiste en un réseau de laboratoires sentinelles, de cabinets sentinelles de soins primaires, de ministères provinciaux et territoriaux de la Santé et d'hôpitaux sentinelles qui publient des rapports sur les sept indicateurs principaux de la grippe au pays sur une base hebdomadaire. L'information est regroupée par le programme Surveillance de l'influenza et est diffusée dans des rapports produits chaque semaine pendant la saison active de la grippe et toutes les deux semaines durant la période de faible activité.

Résultats : Au cours de la semaine 6 , les niveaux régionaux d'activité grippale ont diminuépour six indicateurs de surveillance. Sept régions ont signalé une activité étendue : Ontario (2), Québec (2), Manitoba (1), île-duPrince-Édouard (1) et Terre-Neuve (1). Vingt-et-une régions ont signalé une activité localisée : NouveauBrunswick (7), Nouvelle-Écosse (5), Ontario (5), Alberta (1) et Manitoba (1), et vingt-deux régions ont signalé une activité sporadique. Le taux de consultations national pour le syndrome grippal a diminué par rapport à la semaine précédente pour passer à 44,5 consultation par 1000 habitants, ce qui est supérieur aux niveaux attendus pour la semaine 6 . Un total de 74 éclosions ont été signalées cette semaine et la majorité des éclosions cette saison ont été déclarées dans des établissements de soins de longue durée (ESLD). Les détections de cas de grippe en laboratoire ont diminué par rapport à la semaine précédente, passant de 1874 à la semaine 5 à 1625 à la semaine 6 . Le nombre de tests positifs détectant le virus respiratoire syncytial (VRS) a diminué à 914 détections, ce qui représente 196 cas de moins que le nombre de détections du VRS à la semaine 5; le VRS demeure au deuxième rang parmi les virus les plus souvent détectés, après le virus de la grippe. À ce jour, 4817 hospitalisations dues à la grippe et 342 décès ont été signalés par l'entremise du système de surveillance national des cas graves, la majorité touchant des adultes âgés de 65 ans et plus. Au cours de la saison 20142015, le Laboratoire national de microbiologie (LNM) a caractérisé 194 virus grippaux et a constaté que la majorité des échantillons de la grippe $\mathrm{A}(\mathrm{H} 3 \mathrm{~N} 2)$ testés à ce jour ne présentent pas une concordance optimale avec la souche du vaccin; cependant, tous les virus soumis à des tests de résistance étaient sensibles à l'oseltamivir et au zanamivir. Deux études canadiennes, l'une menée par le Réseau Sentinelle des médecins de surveillance (SPSN) et l'autre par le Réseau canadien des registre d'immunisation (RCRI), ont examiné les données de mi- saison sur l'efficacité du vaccin anti-grippal actuel au Canada. Les deux études ont observé une protection faible ou nulle contre le virus $\mathrm{A}(\mathrm{H} 3 \mathrm{~N} 2)$. (Voir Actualités sur les maladies infectieuses).

Conclusion : Le virus $\mathrm{A}(\mathrm{H} 3 \mathrm{~N} 2)$ continue d'être le type de grippe le plus répandu touchant la population canadienne. Autant dans les détections en laboratoire que dans les hospitalisations et les décès, la majorité des cas ont été signalés chez des personnes âgées de 65 ans ou plus. Les tendances de nombreux indicateurs, tels que les détections en laboratoire et les éclosions, ont été semblables à celles de la saison 2012-2013 dominée par la grippe $A(H 3 N 2)$. Le SPSN et le RCRI rapportent que la majorité des échantillons de la grippe $A(H 3 N 2)$ en circulation ne présentent pas une concordance optimale avec la souche du vaccin. Finalement, plusieurs indicateurs sont en baisse continue depuis la semaine 1, ce qui indique que le pic de la saison grippale 20142015 a eu lieu durant cette semaine 1. Le système de surveillance du programme Surveillance de l'influenza continuera à surveiller l'activité grippale durant tout le reste de la saison 2014-2015 et publiera ses résultats dans le rapport Surveillance de l'influenza. 
Figure 1. Carte de l'activité grippale globale de la grippe/syndrome grippal par province et territoire, Canada, semaine 6, 2015

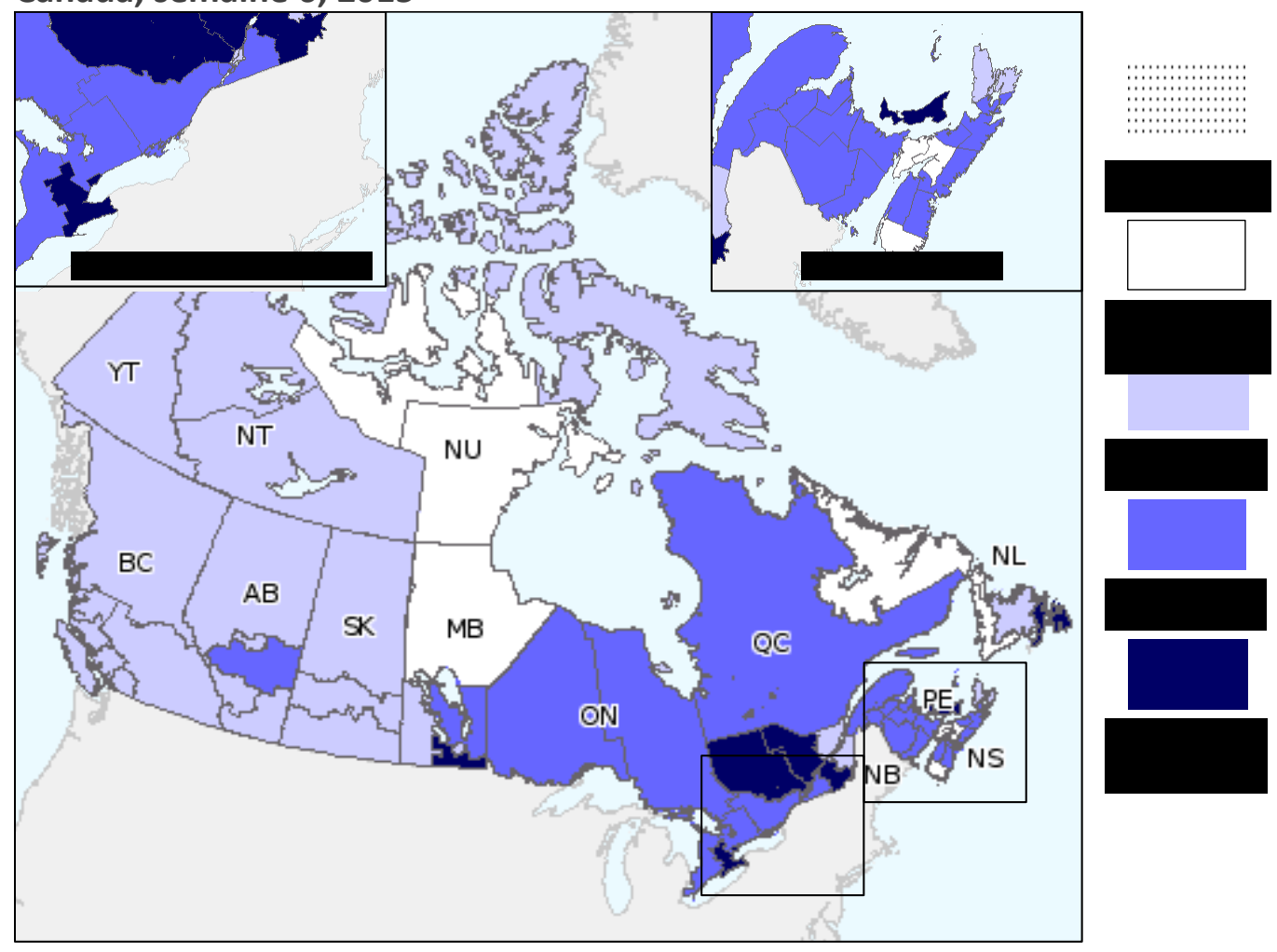

Note : Les niveaux d'activité grippale et pseudogrippale, tels qu'ils sont représentés sur cette carte, sont attribués et enregistrés par les ministères de la Santé provinciaux et territoriaux. Ceci est basé sur les confirmations de laboratoire, les taux de consultation de syndrome grippal des médecins sentinelles et les éclosions. Les définitions détaillées des différents niveaux d'activité, ainsi que les cartes des semaines précédentes, y compris toute mise à jour rétrospective, sont disponibles sur le site Web de Surveillance de l'influenza.

\section{Remerciement}

Les auteurs désirent transmettre leurs remerciements sincères aux partenaires du programme de Surveillance de l'influenza, qui ont participé au programme de Surveillance de l'influenza au cours de la saison grippale de 20142015, y compris les autorités sanitaires provinciales et territoriales, les médecins et les laboratoires sentinelles, le réseau IMPACT, le réseau PCIRN-SOS, le LNM et le CMIOAEZ.

\section{Conflit d'intérêts}

Aucun

\section{Financement}

Aucun

\section{Référence}

(1) Agence de la santé publique du Canada. Surveillance de l'influenza : 8 au 14 février 2015 (semaine 6). http://www.phac-aspc.gc.ca/fluwatch/14-15/index-fra.php 